\title{
Long-term consequences of alcohol misuse in Scottish military veterans
}

\author{
Beverly P Bergman, Daniel F Mackay, Jill P Pell
}

- Additional material is published online only. To view please visit the journal online (http://dx.doi.org/10.1136/ oemed-2014-102234)

Institute of Health and Wellbeing, Public Health \& Health Policy, University of Glasgow, Glasgow, UK

\section{Correspondence to}

Dr B P Bergman, Institute of Health and Wellbeing, Public Health \& Health Policy, University of Glasgow, 1 Lilybank Gardens, Glasgow G12 8RZ, UK;

b.bergman.1@research.gla.ac. uk

Received 19 March 2014 Revised 11 September 2014 Accepted 14 September 2014 Published Online First 1 October 2014

\section{CrossMark}

\footnotetext{
To cite: Bergman $B P$, Mackay DF, Pell JP. Occup Environ Med 2015;72: 28-32.
}

ABSTRACT

Objective Serving military personnel are more likely to drink heavily than civilians. The aim of our study was to examine whether veterans have an increased risk of alcoholic liver disease and alcohol-related death compared with non-veterans.

Design Retrospective cohort study of 57000 veterans resident in Scotland and 173000 age, sex and area of residence-matched civilians, using Cox proportional hazard models to compare the risk of alcoholic liver disease and alcohol-related death overall, by sex, birth cohort, length of service and year of recruitment, adjusting for socioeconomic status.

Results Over mean 29 years follow-up, 677 (1.20\%) veterans developed alcoholic liver disease compared with $2175(1.26 \%)$ non-veterans (adjusted HR=0.91, 95\% Cls 0.84 to $0.99, p=0.035)$. Only the $1945-1949$ veterans' birth cohort was at higher risk, unadjusted $H R=1.25,95 \%$ Cls 1.07 to $1.47, p=0.004$, although their difference in risk became non-significant after adjusting for socioeconomic status, $p=0.052$. The pattern was similar for alcohol-related death. Veterans were less likely than non-veterans to have comorbid hepatitis $\mathrm{C}$. Older age at recruitment at a time of high operational activity in the early 1970s was associated with increased risk, but longer service was not.

Conclusions Overall, veterans in Scotland had a significantly reduced risk of alcoholic liver disease or alcohol-related death compared with non-veterans, although the risk was higher in those born before 1950 . Reasons for the changing pattern are likely to be complex and may reflect operational exposure, social attitudes to alcohol and the impact of recent military health promotion.

\section{INTRODUCTION}

Alcohol misuse accounted for 35926 discharges from acute general hospitals in Scotland in 20122013 and played a part in 1080 deaths in 2012, the highest rates being in men aged 50-54. ${ }^{1}$ A number of studies have shown that military personnel drink more heavily than their civilian peers, ${ }^{2}{ }^{3}$ and that veterans are more likely to develop alcohol-related health problems than those who have never served, although the latter studies are predominantly restricted to veterans of specific conflicts such as Vietnam. ${ }^{4}$ Aguirre et $a l^{5}$ have recently summarised the evidence for the UK Armed Forces' relationship with alcohol, and have identified an association between risky drinking in military personnel (assessed as AUDIT-C score of 5 or higher) and possible mental health problems. Excess alcohol intake

\section{What this paper adds?}

- Previous studies have shown that military personnel drink more heavily than civilians, but little is known about the long-term impact of alcohol on veterans' health.

- This study demonstrates that UK veterans born between 1945 and 1985 and spanning a wide range of periods and lengths of service were less likely overall than non-veterans to develop alcoholic liver disease, or to die from alcohol-related causes, after adjusting for socioeconomic status.

- The oldest veterans had an increased risk of alcoholic liver disease and alcohol-related death compared with non-veterans, although the increase became non-significant after adjusting for socioeconomic status, and the risk reduced in later birth cohorts.

- When stratified by length of service, the risk was highest in Early Service Leavers and reduced with longer service, although the HRs did not generally achieve statistical significance.

is known to be associated with cirrhosis of the liver, cardiomyopathy, pancreatitis, gastritis and polyneuropathy. It increases the risk of oropharyngeal and laryngeal cancer, oesophageal cancer, liver cancer and colorectal cancer, and is associated with increased incidence of stroke, heart failure and breast cancer. $^{6}$ The risk of liver disease increases sharply with the quantity of alcohol consumed. ${ }^{7}$ The UK Government routinely reports alcoholrelated hospital admissions and deaths, but military veterans are not separately identifiable within these data. ${ }^{1}$ There is a paucity of studies reporting the incidence of alcohol-associated harm in veterans, either in the UK or in other nations.

This study uses data from the Scottish Veterans Health Study to examine rates of hospitalisation and death from alcoholic liver disease, and death from alcohol-related conditions, in a large population-based group of veterans spanning a wide range of lengths of service and operational exposures, compared with people with no record of service, and followed up for up to 30 years, in order to examine whether the reported higher alcohol consumption in serving personnel places veterans at an increased risk of alcoholic liver disease or death from alcohol-related causes in the long term. 


\section{METHODS}

\section{Study population}

The Scottish Veterans Health Study is a retrospective cohort study that comprises all 56570 military veterans born between 1945 and 1985 who were registered with National Health Service (NHS) Scotland prior to military service and following discharge, and a 3:1 comparison group of 172753 individuals with no record of military service matched by age, sex and postcode sector of residence (mean population 5000). The study cohort and methods have been described elsewhere. ${ }^{8}$ Participants were identified via their electronic NHS registration records, which provided demographic information as well as the dates of entering and leaving military service. The records were linked, at the individual level, to routine hospital admissions data (Scottish Morbidity Record SMR01), mental healthcare data (Scottish Morbidity Record SMR04) and death certificates to provide information on first episode of hospitalisation due to alcoholic liver disease (defined as International Classification of Diseases (ICD)-10 K70, ICD-9 571.0, 571.1 or 571.2 at any position in the record), death from alcohol-related causes including alcohol-related neuropsychiatric disorders, alcoholic gastritis, alcoholic cardiomyopathy and liver cirrhosis (less primary biliary cirrhosis); defined as ICD-10 F10, G31.2, G62.1, I 42.6, K29.2, K70, K73, K74, K86.0, X45, X46 and 15 , and mapped to ICD-9 as $303.0,303.9$, 305.0, 291.*, 357.5, 425.5, 535.3, 571.* (less 571.5, 571.6 and 571.8), 577.1 and E860.9 and all deaths. The ICD codes for alcoholrelated death were selected in accordance with the UK National Statistics classification, which includes only those causes regarded as being most directly due to alcohol consumption. It does not include other diseases where some causal relationship with alcohol has been shown, such as stomach cancer, or external causes of death where alcohol may be a factor, such as road traffic accidents. ${ }^{9}$ Data on admissions for hepatitis C and on mental healthcare episodes for a diagnosis of acute stress or adjustment reaction or post-traumatic stress disorder (PTSD); defined as ICD-9 308-309 or ICD-10 F43*, were also obtained.

Data were available on health events that occurred from the start of Scottish linked health records on 1 January 1981 to 31 December 2012 inclusive. Prescribing data for a limited number of drugs, based on dispensed prescriptions, were available from 2009 onwards from the NHS Prescribing Information System. Data were provided for all drugs recognised in the British National Formulary for relapse prevention in alcohol dependence, aggregated as 'alcohol abstinence therapy' for the purposes of the data set, but were not broken down by individual drug. The data extract was pseudoanonymised and approval for the study was granted by the Privacy Advisory Committee of the Information Services Division of NHS Scotland.

\section{Socioeconomic status}

Details of the Scottish Index of Multiple Deprivation (SIMD) are published by the Scottish Government. ${ }^{10}$ In Scotland, there are 6505 datazones, based on postcode of residence, with a mean population of 800 . The SIMD for each datazone is derived from information on income, employment, health, education (including skills and training), housing, crime and access to services. It has been used to derive quintiles of regional socioeconomic status (SES) for the Scottish population; ranging from 1 (most deprived) to 5 (least deprived). We used postcode of postservice residence to categorise the cohort participants according to the general population quintiles.

\section{STATISTICAL METHODS}

Cox proportional hazard models were used to examine the association between veteran status and cumulative risk of alcoholic liver disease, using age as the time dependent variable and age at first record of alcoholic liver disease or death (if no record of alcoholic liver disease) as the censor time. We also examined the association with hepatitis $\mathrm{C}$ or severe stress/PTSD as comorbidities in veterans and non-veterans with a diagnosis of alcoholic liver disease. HRs and $\mathrm{p}$ values were calculated and the a priori rejection level was set at 0.05 . Proportionality was tested using methodology based on Schoenfeld residuals. ${ }^{11}$ The models were run univariately and then repeated adjusting for the potential confounding effect of regional SES quintile. The analyses were repeated by grouped year of birth, stratified in 5-year bands, to examine birth cohort effects. Further subgroup analyses were undertaken to examine the effect of the length of service, in categories reflecting common UK periods of military engagement. Length of service in these categories is broadly related to highest rank achieved. Kernel density plots were used to assess patterns of changing risk of alcoholic liver disease by year of entry to service in comparison with the number recruited in each year, and the relationship to the year of diagnosis. All-cause mortality in those with a diagnosis of alcoholic liver disease was calculated, and Cox proportional hazard models were used to examine the association between mortality due to all alcohol-related causes and veteran status as well as length of service. All analyses were performed using Stata V.12.1 (copyright 1985-2011 StataCorp).

\section{RESULTS}

After data cleansing, 56205 (99.3\%) veterans and 172741 (99.9\%) non-veterans were included in the analysis. There were 50970 (90.7\%) male veterans and 5235 (9.3\%) female, reflecting the gender balance of the Armed Forces. The mean period of follow-up was 29.3 years, and there was a total of 6.7 million person years of follow-up among veterans and non-veterans combined. During the period of follow-up, 677 (1.20\%) of the veterans had a diagnosis of alcoholic liver disease compared with $2175(1.26 \%)$ of the non-veterans. The difference was not statistically significant in the unadjusted model, $\mathrm{HR}=0.97,95 \%$ CIs 0.89 to $1.06, p=0.487$. After adjusting for regional SES, the veterans were less likely to have a diagnosis of alcoholic liver disease, $\mathrm{HR}=0.91,95 \% \mathrm{CI} 0.84$ to $0.99, \mathrm{p}=0.035$. Male cases represented $651(1.28 \%)$ of the veterans and $2049(1.35 \%)$ of the non-veterans, while female cases represented only 26 $(0.50 \%)$ of the veterans and $126(0.61 \%)$ of the non-veterans. Testing for interaction with sex was non-significant, $\mathrm{p}=0.550$. There was a statistically significant reduction in risk between veterans and non-veterans in men after adjusting for SES, although not in women where the small number of cases provided insufficient statistical power (table 1).

Testing for interaction with birth cohort was highly significant, $\mathrm{p}<0.001$. Stratifying by birth cohort, analysing men and women together, showed a gradient of reducing risk over time. Only the 1945-1949 birth cohort showed a statistically significant increase for veterans in the univariate Cox proportional hazard model $(\mathrm{HR}=1.25$, 95\% CI 1.07 to $1.47, \mathrm{p}=0.004)$, although this reduced and did not achieve significance after adjusting for regional SES $(\mathrm{HR}=1.17,95 \%$ CI 1.00 to 1.36 , $\mathrm{p}=0.052$ ). For the $1955-1959$ birth cohort there was a statistically significant reduction in risk in the multivariable model, and for the 1960-1964 birth cohort veterans were at statistically significantly reduced risk in the univariable and multivariable models (table 1 and online supplementary figure). 
Table 1 Cox proportional hazard model of the association between veteran status and risk of alcoholic liver disease*

\begin{tabular}{|c|c|c|c|c|c|c|c|}
\hline & \multirow[b]{2}{*}{ Cases (veterans) } & \multicolumn{3}{|c|}{ Univariable } & \multicolumn{3}{|c|}{ Multivariable } \\
\hline & & HR & $95 \% \mathrm{Cl}$ & $p$ Value & HR & $95 \% \mathrm{Cl}$ & $p$ Value \\
\hline Overall & 677 & 0.97 & 0.89 to 1.06 & 0.487 & 0.91 & 0.84 to 0.99 & 0.035 \\
\hline Males & 651 & 0.96 & 0.88 to 1.05 & 0.418 & 0.90 & 0.82 to 0.98 & 0.019 \\
\hline Females & 26 & 0.84 & 0.55 to 1.29 & 0.439 & 0.85 & 0.56 to 1.30 & 0.464 \\
\hline \multicolumn{8}{|c|}{ Birth cohort (5-year groups) } \\
\hline 1945-1949 & 222 & 1.25 & 1.07 to 1.47 & 0.004 & 1.17 & 1.00 to 1.36 & 0.052 \\
\hline 1950-1954 & 202 & 1.02 & 0.87 to 1.20 & 0.768 & 0.93 & 0.79 to 1.09 & 0.364 \\
\hline 1955-1959 & 152 & 0.85 & 0.71 to 1.02 & 0.076 & 0.79 & 0.66 to 0.94 & 0.010 \\
\hline 1960-1964 & 63 & 0.69 & 0.52 to 0.90 & 0.007 & 0.70 & 0.53 to 0.91 & 0.009 \\
\hline 1965-1969 & 29 & 0.77 & 0.51 to 1.14 & 0.195 & 0.84 & 0.56 to 1.26 & 0.409 \\
\hline 1970-1974 & 9 & 0.55 & 0.26 to 1.17 & 0.121 & 0.62 & 0.29 to 1.30 & 0.205 \\
\hline
\end{tabular}

${ }^{*}$ Alcoholic liver disease $=$ K70, 571.0-571.3.

Among those with alcoholic liver disease, $2.27 \%$ of veterans had hepatitis $\mathrm{C}$ compared with $4.97 \%$ of non-veterans $(\mathrm{OR}=0.47,95 \%$ CI 0.27 to $0.80, \mathrm{p}=0.004)$. When people with hepatitis $\mathrm{C}$ were excluded, the association between veteran status and alcoholic liver disease was the same (adjusted $\mathrm{HR}=0.92,95 \%$ CI 0.84 to $1.00, \mathrm{p}=0.064$ ). Stress or PTSD (of sufficient severity to warrant day care or secondary care admission) was strongly associated with alcoholic liver disease in veterans and non-veterans, adjusted $\mathrm{HR}=4.35,95 \% \mathrm{CI} 3.06$ to 6.17, $\mathrm{p}<0.001$ in veterans and adjusted $\mathrm{HR}=3.50,95 \% \mathrm{CI}$ 2.69 to $4.54, \mathrm{p}<0.001$ in non-veterans. However, veterans with a diagnosis of stress or PTSD were not at statistically significantly greater risk of alcoholic liver disease than non-veterans with stress or PTSD, adjusted $\mathrm{HR}=1.04$, 95\% CI 0.68 to 1.59 , $\mathrm{p}=0.870$.

The kernel density plot for veterans with alcoholic liver disease by year of entry to service showed a peak corresponding to those who entered service in around 1971, which was disproportionate to the number recruited (figure 1), and the Cox proportional hazard model confirmed an increased risk in those who joined in 1970 and 1971, unadjusted $\mathrm{HR}=1.27$, 95\% CI 1.06 to $1.53, p=0.011$, although the difference did not reach statistical significance after adjusting for regional SES, $\mathrm{HR}=1.12,95 \%$ CI 0.93 to $1.34, \mathrm{p}=0.242$. A Lexis diagram of

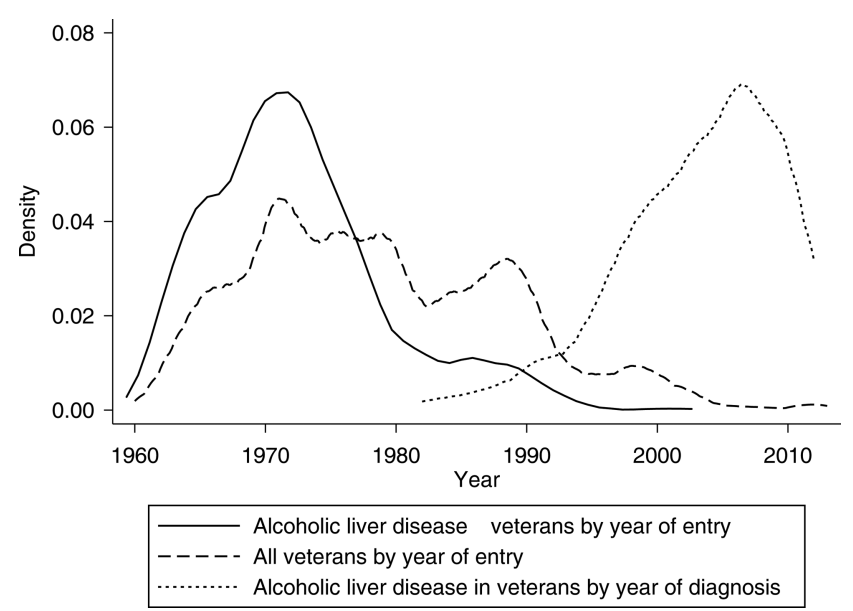

Figure 1 Kernel density plot of hospitalisation or death due to alcoholic liver disease in veterans by year of entry to service and year of diagnosis. All veterans by year of entry for comparison. absolute risk by year of birth and year of entry demonstrated the highest incidence to be in those born 1946-1949 inclusive who joined for service in 1969, 1970 and 1971. When analysed by length of service, comparing each category of Service personnel with all non-veterans, there was no clear pattern. There was a statistically significant increase in risk for those with less than 3 years' service (Early Service Leavers, who have left the services prior to completion of the minimum term of engagement) but this became non-significant after adjusting for SES, while there was a decrease in risk in the longer serving groups, which was statistically significant in those with 4-6 years' service (table 2). There was no increase in risk compared with non-veterans in those Early Service Leavers who left prior to completion of initial training.

All-cause mortality in those with a diagnosis of alcoholic liver disease was $445 / 677$ (65.7\%) in veterans compared with 1361/ $2175(62.6 \%)$ in non-veterans. The difference was not statistically significant, unadjusted $\mathrm{OR}=1.05,95 \%$ CI 0.99 to 1.12 , $\mathrm{p}=0.137$.

Death from alcohol-related causes was recorded in 356 $(0.63 \%)$ veterans compared with 1147 (0.66\%) non-veterans. The difference was not statistically significant, unadjusted $\mathrm{OR}=0.96,5 \%$ CI 0.88 to $1.06, \mathrm{p}=0.435$. The Cox proportional HR was $0.95,95 \%$ CI 0.84 to $1.07, \mathrm{p}=0.412$ unadjusted; there was an overall reduction in risk which was statistically significant after adjusting for SES, $\mathrm{HR}=0.88,95 \% \mathrm{CI} 0.79$ to $1.00, p=0.044$. Subgroup analysis by birth cohort showed an increased risk only in the 1945-1949 cohort, unadjusted $\mathrm{HR}=1.28$, 95\% CI 1.03 to $1.58, \mathrm{p}=0.026$, but this became non-significant after adjusting for SES, $\mathrm{HR}=1.19$, 95\% CI 0.96 to $1.47, \mathrm{p}=0.113$.

Veterans with a diagnosis of alcoholic liver disease were less likely than non-veterans to have received a prescription for alcohol abstinence drugs although the difference did not achieve statistical significance, $\mathrm{OR}=0.79,95 \% \mathrm{CI} 0.79$ to 1.17 , $\mathrm{p}=0.234$

\section{DISCUSSION}

Data from the Scottish Veterans Health Study demonstrated that overall, veterans were at no greater risk of alcoholic liver disease or alcohol-related death than the general population, and they were at slightly but significantly reduced risk after adjusting for regional SES. The overall rate of alcoholic liver disease, for veterans and non-veterans, was similar to the $1.13 \%$ population prevalence reported in the Italian Dionysus Study, which also 
Table 2 Cox proportional hazard model of the association between length of service and risk of alcoholic liver disease*

\begin{tabular}{|c|c|c|c|c|c|c|c|}
\hline \multirow[b]{2}{*}{ Length of service§ } & \multirow[b]{2}{*}{ Cases (veterans) } & \multicolumn{3}{|c|}{ Univariablet } & \multicolumn{3}{|c|}{ Multivariableł } \\
\hline & & HR & $95 \% \mathrm{Cl}$ & $\mathrm{p}$ Value & HR & $95 \% \mathrm{Cl}$ & $\mathrm{p}$ Value \\
\hline Basic training & 73 & 0.92 & 0.73 to 1.16 & 0.487 & 0.81 & 0.64 to 1.02 & 0.070 \\
\hline$\leq 3$ years (postbasic training) & 190 & 1.25 & 1.07 to 1.45 & 0.004 & 1.06 & 0.91 to 1.23 & 0.427 \\
\hline $4-6$ years & 118 & 0.89 & 0.74 to 1.07 & 0.209 & 0.77 & 0.64 to 0.92 & 0.006 \\
\hline $7-9$ years & 101 & 1.11 & 0.91 to 1.36 & 0.288 & 1.01 & 0.83 to 1.25 & 0.855 \\
\hline $10-12$ years & 64 & 0.89 & 0.70 to 1.15 & 0.373 & 0.85 & 0.66 to 1.09 & 0.208 \\
\hline $13-16$ years & 42 & 0.80 & 0.59 to 1.09 & 0.152 & 0.76 & 0.56 to 1.04 & 0.088 \\
\hline $17-22$ years & 38 & 0.75 & 0.54 to 1.03 & 0.080 & 0.81 & 0.59 to 1.12 & 0.209 \\
\hline Over 22 years & 50 & 0.78 & 0.59 to 1.03 & 0.082 & 0.97 & 0.73 to 1.29 & 0.832 \\
\hline
\end{tabular}

showed that only $5.5 \%$ of those drinking more than $30 \mathrm{~g}$ alcohol per day had evidence of alcoholic liver damage. ${ }^{12}$ Subgroup analysis of our data set showed a complex picture of changing risk over time. There was an increased risk of alcoholic liver disease and alcohol-related death in the earliest birth cohort (born 1945-1949) although this lost statistical significance after adjusting for regional SES. The increase arose predominantly from people born 1946-1949 who joined the services 1970-1971 and who were older than the majority of recruits at entry to service. Younger veterans were at lower risk than age-matched non-veterans. Fewer of the veterans with alcoholic liver disease had comorbid hepatitis $\mathrm{C}$, suggesting that drug misuse was less prevalent in veterans than non-veterans. The $2.8 \%$ prevalence of comorbid hepatitis $\mathrm{C}$ was much lower than the prevalence of $18.4 \%$ reported in a study of US veterans with alcoholic liver disease. ${ }^{13}$

The misuse of alcohol by military personnel has long been recognised as a problem, leading to disciplinary offences, illhealth and premature mortality as identified in an early UK study. ${ }^{14}$ However, we have identified no studies of incidence or prevalence of the long-term consequences of alcohol misuse in the veterans' community, although Robinette et al $l^{15}$ reported increased all-cause mortality in US World War II veterans who had previously been diagnosed with chronic alcoholism.

The finding of a specific period of entry to service, which was associated with an especially high risk of developing alcoholic liver disease, centred around 1970-1971 and predominantly affecting those aged 21 years and over at entry, may be related to intense operational activity. Although we have no data on individual deployment history, the majority of military personnel saw service in Northern Ireland during that period, following the start of operations there in late 1969. We found that older age on entry to service, at a time when early deployment was likely, was associated with increased risk of later alcoholic liver disease. Lynch examined alcohol-related deaths in serving British Army personnel for the decade 1968-1977 and found an incidence of 12.36/100 000 personnel, for deaths occurring off-duty. The mean age at death was 24 years. There was an increase in the number of deaths from acute alcohol poisoning in the latter half of the period. ${ }^{16}$ Further examination of Lynch's data shows a mean of 1.8 deaths per year from acute alcohol poisoning between 1968 and 1972 compared with a mean of 5.2 per year between 1973 and 1978, an increase of nearly $200 \%$. With hindsight, it seems probable that operational deployment contributed to the increased toll of alcohol-related deaths. The finding of a substantially increased risk of alcoholic liver disease beginning 20 years later and peaking at around 36 years, in those recruited in 1970-1971, provides support for this hypothesis.

A study of US Vietnam veterans found that increasing age on deployment was associated with a lower risk of PTSD,${ }^{17}$ but did not consider age at entry to service. Risk aversion has been shown in numerous studies to increase with age, although most studies have been based on financial risk rather than physical risk. ${ }^{18}$ We postulate that the more mature recruits may have bonded poorly with their younger peers and may have felt especially vulnerable and marginalised, leading to later seeking solace in alcohol.

Overall, we found that the risk of alcoholic liver disease in Armed Forces personnel has reduced over time. Recent publications have focused on alcohol misuse as a consequence of the mental health impacts of combat exposure and have largely overlooked the social role of alcohol. ${ }^{2}$ Evidence from the Scottish Veterans Health Study and a re-evaluation of Lynch's paper $^{16}$ now suggest that there is a complex relationship. Operational exposure in the early 1970s may have been associated with a lasting increase in the level of alcohol use in some people following departure from the operational situation. Underpinning factors may have included an intense social response to the removal of restrictions imposed during deployment and the general increase in risk-taking behaviour following combat exposure, which has been described elsewhere, ${ }^{19}{ }^{20}$ in addition to the role played by the as-then largely unrecognised psychological effects of operational deployment. The Scottish Veterans Health Study has demonstrated that a small subgroup of older veterans may be at increased risk of alcoholic liver disease, compared with non-veterans and with later generations of Service personnel.

In the late 1970 s and early 1980 s, the military drinking culture began to change, as part of a general transition to a fitness-orientated culture. Over a period of around 20 years, drunkenness, and especially lunchtime drinking, became less acceptable as the British Armed Forces became aware of the problems of heavy drinking and began to implement health promotion strategies. ${ }^{21}$ Army policy and regulations discouraged drunkenness off-duty and it remained a punishable offence to be drunk at any time, ${ }^{22}$ but it may be argued that the most powerful driver was peer example and pressure; the societal drinking 'norm' is a powerful driver of behaviour, especially in younger people and in a group-orientated culture such as the Armed Forces. ${ }^{23} 24$ Personnel born after 1960 joined the Armed Forces in the late 1970s; their overall reduction in risk has been 
demonstrated in our study. Recent generations of Service personnel show a decreasing risk of alcoholic liver disease, and a lower risk than in non-veterans, suggesting that in-service health promotion has been effective, although isolated extreme episodes of alcohol misuse still occur. ${ }^{25}$

There is considerable interest in alcohol behaviour in relation to current and recent operations. One UK study showed an increase in heavy drinking behaviour (defined as $>20$ units per week) between the Gulf War (1991) and the Iraq War (2003), irrespective of deployment history, in men and women. ${ }^{26}$ Because of the long lead time for the development of alcoholic liver disease, it is impossible to predict the impact of current operations on future alcohol-related harm in veterans.

The strengths of the present study are that it was based on a large cohort covering the whole of Scotland with up to 30 years' follow-up. The diagnoses were taken from hospital admission and death records, and are therefore likely to be reliable and reasonably complete in respect of those events occurring within Scotland. The use of record linkage to analyse individual level data directly derived from health records allowed a robust cohort study design to be employed. The results were able to be matched or adjusted for potential confounders including sex and regional SES. It was possible to perform subgroup analysis by sex, birth cohort, year of entry to service and length of service, contributing to the understanding of factors influencing veterans' health. The large number of study participants and long follow-up period increases the likelihood that the results represent a true picture of the risk.

Limitations of the study include possible loss to follow-up of participants due to their migration from Scotland, which could not be quantified, and the lack of any follow-up data prior to the start of linked health data collection in Scotland from 1 January 1981, although as the oldest of the cohort were only aged 36 years at that date, the number affected by alcoholic liver disease by then is likely to be small. For those who are military veterans, we have not been able to link to in-service health or service records and thus alcoholic liver disease occurring during service will not have been captured until the individual left the service and returned to NHS care. The 'healthy worker effect' is unlikely to have affected the findings of this study since the long lead time for the development of alcoholrelated health problems means that most people will have left the Armed Forces before any symptoms develop. Individuallevel deployment data was unavailable to us; because the data set was derived from demographic, vital record and hospital admissions data, no information was available on individual combat exposure or personal lifestyle risk factors such as smoking or alcohol intake. Therefore, we were able neither to analyse the impact of these factors nor adjust for them. We have inferred deployment history, in broad terms, based on UK military campaign history. Veterans with Reserve service only could not be identified from NHS records and were therefore included among the non-veterans; this would have had the effect of reducing any observed differences between veterans and non-veterans.

\section{CONCLUSION}

Overall, veterans are at significantly reduced risk of alcoholic liver disease or alcohol-related death compared with nonveterans after adjusting for SES. There is a small non-significant increase in risk for those born before 1950, while veterans born later show a decreasing risk. There is also an increase in risk for those who entered the Armed Forces in the early 1970s, which may be related to operational intensity and heavy social drinking early in their service. There is evidence to suggest that recent health promotion initiatives have been effective in minimising long-term harm due to alcohol.

Acknowledgements The authors thank the NHS Central Registry (NHSCR) and the Information Services Division, NHS Scotland (ISD) for extracting and linking the data set.

Contributors BPB contributed to the conception and design of the study with advice from JPP and DFM. BPB analysed and interpreted the data, and prepared the first draft of the article. Data analysis was overseen by DFM. BPB, DFM and JPP reviewed, edited and approve the final article.

Competing interests None.

Ethics approval Privacy Advisory Committee, NHS ISD Scotland.

Provenance and peer review Not commissioned; externally peer reviewed.

\section{REFERENCES}

1 ISD Scotland. Alcohol-related Hospital Statistics Scotland 2012/13. Scotland: NHS Scotland, 2014.

2 Jones E, Fear NT. Alcohol use and misuse within the military: a review. Int Rev Psychiatry 2011;23:166-72.

3 Fear NT, Iverson A, Meltzer $\mathrm{H}$, et al. Patterns of drinking in the UK Armed Forces. Addiction 2007;102:1759.

4 Jordan B, Schlenger WE, Hough R. Lifetime and current prevalence of specific psychiatric disorders among Vietnam veterans and controls. Arch Gen Psychiatry 1991:48:207-15

5 Aguirre M, Greenberg N, Sharpley J, et al. Alcohol consumption in the UK armed forces: are we drinking too much? J R Army Med Corps 2014;160:72-3.

6 World Health Organisation. International guide for monitoring alcohol consumption and related harm. Geneva: World Health Organisation, 2000.

7 Becker U, Deis A, Sorensen TI, et al. Prediction of risk of liver disease by alcohol intake, sex, and age: a prospective population study. Hepatology 1996;23:1025-9.

8 Bergman BP, Mackay DF, Pell JP. Acute myocardial infarction in Scottish military veterans: retrospective cohort study of 57,000 veterans and 173,000 matched non-veterans. Am J Epidemiol 2014;179:1434-41.

9 Office for National Statistics. Alcohol-related deaths in the United Kingdom, registered in 2012. London: National Statistics, 2014:26.

10 Scottish Goverment. Scottish Index of Multiple Deprivation 2012. Edinburgh: Scottish Government, 2012.

11 Grambsch PM, Therneau TM. Proportional hazards tests and diagnostics based on weighted residuals. Biometrika 1994;81:515-26.

12 Bellentani S, Saccoccio G, Costa G, et al. Drinking habits as cofactors of risk for alcohol induced liver damage. Gut 1997:41:845-50

13 Mendenhall CL, Moritz T, Rouster S, et al. Epidemiology of hepatitis C among veterans with alcoholic liver disease. Am J Gastroenterol 1993;88:1022-6.

14 Dunbar-Miller RA. Alcohol and the fighting man-an historical review. J R Army Med Corps 1984;130:117-21.

15 Robinette CD, Hrubec Z, Fraumeni JF. Chronic alcoholism and subsequent mortality in World War II veterans. Am J Epidemiol 1979;109:687-700.

16 Lynch P. Alcohol associated deaths in British soldiers. J R Army Med Corps 1987;133:36.

17 King DW, King LA, Foy DW. Prewar factors in combat-related posttraumatic stress disorder: structural equation modeling with a national sample of female and male Vietnam veterans. J Consult Clin Psychol 1996;64:520-31.

18 Wang H, Hanna SD. Does risk tolerance decrease with age? Financ Couns Plann 1998;8:27-31.

19 Killgore WDS, Cotting DI, Thomas JL, et al. Post-combat invincibility: violent combat experiences are associated with increased risk-taking propensity following deployment. J Psychiatr Res 2008:42:1112-21.

20 Fear NT, Iversen A, Chatterjee A, et al. Risky driving among regular Armed Forces pesonnel from the United Kingdom. Am J Prev Med 2008;35:230-6.

21 Personnel Services 2 (Army). A Junior Commander's guide to alcohol misuse. Ministry of Defence, 1998.

22 Army Act. 3 \& 4 Eliz. 2 Ch. 18, 43. 1955.

23 Dielman TE, Campanelli PC, Shope JT, et al. Susceptibility to peer pressure, self-esteem, and health locus of control as correlates of adolescent substance abuse. Health Educ Behav 1987;14:207-21.

24 Selnow GW, Crano WD. Formal vs informal group affiliations: implications for alcohol and drug use among adolescents. J Stud Alcohol 1986;47:48-52.

25 Evans SJ. Soldier died after downing 16 shots of "Top Shelf" alcohol. Daily Mail. 3 Dec 2013. http://www.dailymail.co.uk/news/article-2517718/Buckley-Barrackssoldier-Andrew-Murgatroyd-died-downing-16-shots.html (accessed 13 Mar 2014).

26 Rona RJ, Fear NT, Hull L, et al. Women in novel occupational roles: mental health trends in the UK Armed Forces. Int J Epidemiol 2007;36:319-26. 